\title{
Experimental Study of Solar Water Heater under the Libyan Climate Conditions
}

\author{
Ali. J. S. Alrafad ${ }^{1}$, Abdihg S. Alrafad ${ }^{1}$, Tarek. Hamad ${ }^{2} \&$ Ahmed. Nassar $^{3}$ \\ ${ }^{1}$ Mechanical Engineering Department, High institute of Science and technology, Algobi, Altmimi - Libya \\ ${ }^{2}$ Department of Sustainable and Renewable Energy Engineering, Omar Al-Mukhtar University, El-Bieda, Libya. \\ ${ }^{3}$ Mechanical Engineering Department, Bright star university - Libya \\ Correspondence: Ali Jibreel Saed, Mechanical Engineering Department, High institute of Science and \\ technology, Altmimi-, Libya. E-mail: alidosh85@yahoo.com
}

Received: March 29, 2020

Accepted: August 19, 2020

Online Published: August 27, 2020

doi:10.5539/mas.v14n9p28

URL: https://doi.org/10.5539/mas.v14n9p28

\begin{abstract}
In our modern societies, One of the main and simplest signature traits is hot water as a convenient and efficient way of life either for industrial and domestic purposes, however, obtaining hot water in most cases will be through fossil fuel either by direct burning for the fuel for heating or indirectly by using electricity that generated by fossil fuel. Using solar heaters will limit the in some extent the usage of fossil fuel.

A flat solar water heater of (165 to 175$) \mathrm{cm}^{3}$ has been constructed to be used as a model for educational purposes. The solar heater is made of local materials consist of galvanized iron pipes, glass surfaces, wool insulation, aluminum frame, and fixed iron base. Moreover, Thermocouples, pyranometer, and an anemometer were used to test the performance of the heater in four days in May for the angle of inclination of the complex 320 is on the horizontal. In conclusion, the daily average efficiency was around $57 \%$. The temperature in the tank is about $62{ }^{\circ} \mathrm{C}$ at noon, which is sufficient for home use throughout the day.
\end{abstract}

Keywords: solar heater, thermal, water, renewable energy

\section{Introduction}

Energy has the biggest impact on any country's socio-economic growth. Therefore, due to economic and technological advances around the world, energy demand over the 2006-2030 forecast period will increase by a total of $44.2 \%$ (Mohamed \& Lee, 2006).

However, a significant proportion of the energy comes from fossil fuel, and it is well known that burning fossil fuels emit gaseous emissions, which are responsible for the effects of global warming and greenhouse gases. Those processes will result in global climate change, depletion of stratospheric ozone, loss of biodiversity; changes in hydrological systems and freshwater sources, land degradation and increase of stress on food-producing systems(Leo, 1996). Therefore, several countries around the world are using renewable energy to address environmental problems related to the use of fossil fuels, not just to generate electricity, but also to address environmental problems(Harikrishnan, Deepak, \& Kalaiselvam, 2014).

The use of renewable energy, particularly solar energy, is therefore very important in terms of harnessing environmentally friendly clean energy. In virtually all residential or industrial houses. whether, over the roof, there is space that can be used by installing solar energy systems such as solar water heaters, PV modules. Rooftop solar systems are today the exclusive, innovative and competitive solutions available on the market(Hu, $\mathrm{Li}, \mathrm{Gao}, \&$ Yin, 2014).

Solar energy is likely to be one of the most promising sources of renewable energy over the next few decades, and in reality, it is particularly important in countries such as Spain, Germany, China, the USA, India, Malaysia, Bangladesh and some other countries that have abundant high solar intensity(A.Azouz, 2019b; Mohsen, Al-Ghandoor, \& Al-Hinti, 2009; Sarhaddi, Farahat, Ajam, Behzadmehr, \& Adeli, 2010). The solar energy applications can be divided into two categories:

(1) Photovoltaic (PV) system, which converts solar energy into electrical energy.

(2) The solar thermal system, which converts solar energy into thermal energy like a solar water heater. 
The solar collector (water heater) is an important element in the solar energy system because it absorbs solar radiation and transforms it into a useful source of heat energy which can be used to perform specific tasks (A.Azouz, 2019a; Chamoli \& Thakur, 2014; Farahat, Sarhaddi, \& Ajam, 2009).

The majority of SWH systems used are of the type of thermosyphon that Consists of a water grid that carries tubes bonded to the absorber layer, Or with fluid flow channels, together with a separate fluid storage system(Akuffo \& Jackson, 1988).

There are a variety of different collectors of solar energy but they are either stationary or concentrated. In first the stationary type includes flat-plate collectors, evacuated tube collectors, and parabolic compound collectors, while the concentration type includes: parabolic and cylindrical collectors by collector, parabolic dish reflector and heliostat field collector (Chong, Chay, \& Chin, 2012; Ibrahim et al., 2009).

A flat-plate collector is a non-concentrating collector in which the absorbing surface is designed. A standard flat-plate solar collector consists of the following main components: (a) a transparent top cover, (b) a collector plate, (c) an insulation system and (d) a casing. Solar water heating systems can usually be easily constructed according to (a) passive (gravity, natural convection, thermosyphon) or active (forced circulation, pumped) systems; (b) direct and indirect systems; (c) pressurized and non-pressurized (open, drain down) systems (Pandey, Tyagi, Rahim, Kaushik, \& Tyagi, 2015; Sharma, 2014; Vickers, 2017; Zondag, 2008).

In this study, a solar water heater model is constructed to estimate the thermal performance.This study also foucses on the use of solar energy to heat water in Altmimi, Libya.

\section{Method}

The flat solar water heater has been manufactured from a cheap local materials, so that the circulation of water between the solar collector and the tank is normal. The heater has been manufactured and can be moved by an iron platform with fixed bases with an area of (150 to 180) $\mathrm{m} 2$ and can be used as an educational device.The device consists mainly of several components, each of which will be explained in detail as follows: device components.

\subsection{Absorbent Surface s}

The absorbent surface is one of the key parts of the solar collector, it absorbs the incident solar radiation on it, and turn it into heat to be used for heating water. The absorbent surface can be galvanized iron, aluminum or copper, so as to absorb the greatest amount of solar energy falling on the complex.

The absorbent surface of galvanized iron was chosen for its abundance in the market as well as for its cheap price. The absorbent surface is formed as shown in Figure 1 and the absorbent surface is formed in the following steps:

1) Aluminum mold length $1740 \mathrm{~mm}$, width $830 \mathrm{~mm}$ and thickness $2 \mathrm{~mm}$ were selected.

2) The aluminum mold is milled in the form of a half cylinder along the mold with a diameter of $43 \mathrm{~mm}$.

3) Galvanized iron sheet with thickness $0.8 \mathrm{~mm}$ is placed on the aluminum mold.

4) Place the galvanized iron sheet on the aluminum core The rivet is installed with rivets from both sides 230 $\mathrm{mm}$ from the end of the mold to make parallel cavities to ensure that the absorbent plate does not move on the aluminum mold.

5) A solid rod of length $1560 \mathrm{~mm}$ and diameter $16 \mathrm{~mm}$ is selected and placed over the absorbent plate and then knocked on the absorbent rod. Half cylinder in the absorbent plate.

6) Repeat step (5) until the remaining cavities are formed $76 \mathrm{~mm}$ from the center of each cavity in the absorbent plate.

7) In the same steps, another absorbent surface was formed in the same form with an increase in the space. The spaces between the pipes were left from the absorbent surface to ease the heat transfer.

8) Welded galvanized iron pipes with the upper collector tube and the lower collector pipe are placed between the plates and then fix the plates by screws while ensuring that the pipes are stacked well to the plates.

After that paint is used to color the absorbent surface with black to absorb as much of the falling solar energy as possible and to reduce the sun's reflection. 


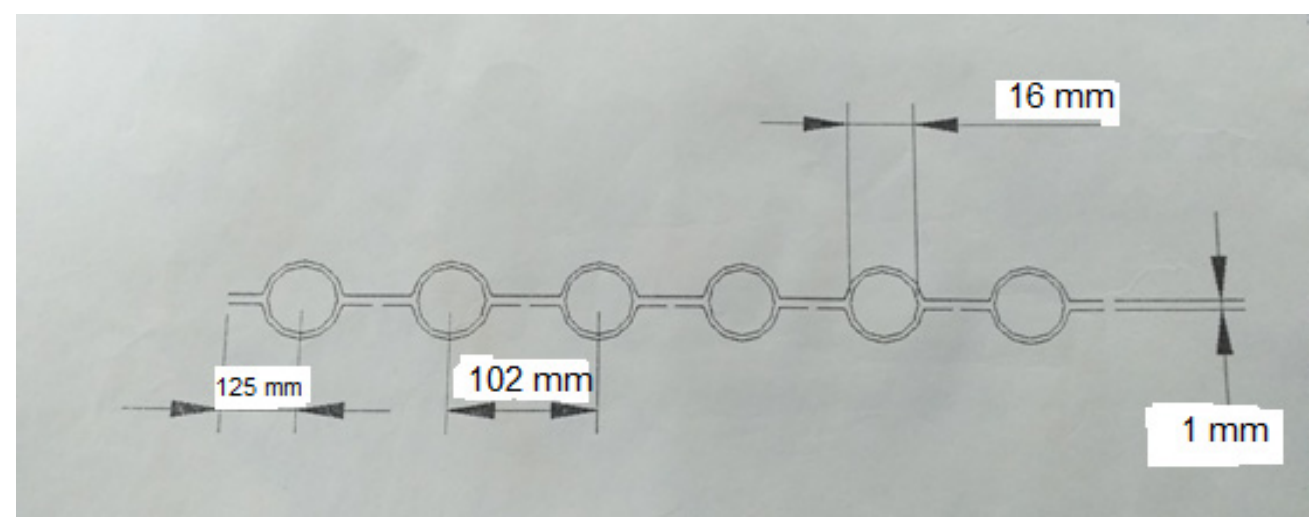

Figure 1. The absorbent surface after forming

\subsection{Hot water Connection Pipes}

Aluminum, iron or copper pipes are used in solar heaters to pass water through it, pipes has been used are made of galvanized iron diameter $16 \mathrm{~mm}$ and length $1560 \mathrm{~mm}$ and the apparent length is $1540 \mathrm{~mm}$ on the absorbent surface either $20 \mathrm{~mm}$ and enters the upper and lower collector pipe Bala co-acetylene oxy-acetylene is welded and there are several ways to fix the pipes on the absorbent surface.

The method used is described in Figure 2 to complete the implementation of the absorbent plate with the pipes in order to take the advantage of the maximum amount of incident solar radiation on the pool to heat water.

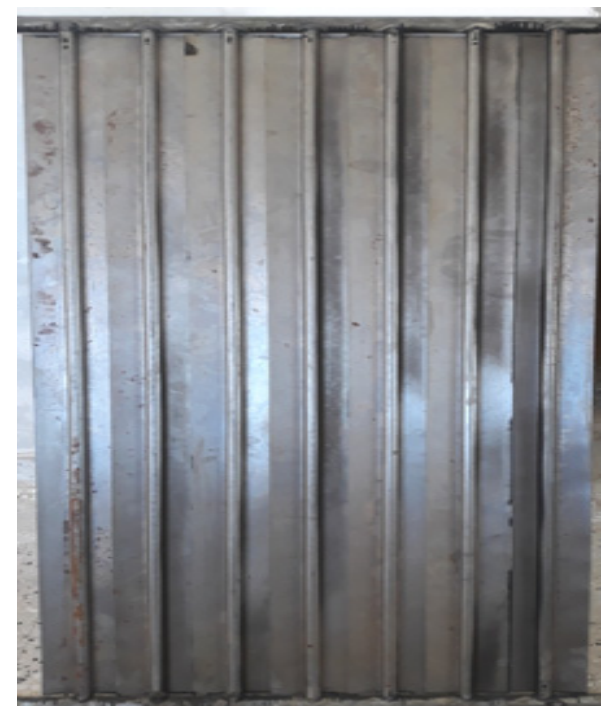

Figure 2. The method of fixing pipes on the surface of the pipette

Galvanized iron pipes were selected for their abundance in the market and cheaply as well as high thermal conductivity. In order to absorb heat from the absorbent surface quickly and at the same time this heat is also transferred to the water quickly through galvanized iron pipes.

Whereas, the diameter of the pipes connecting the ideal water is within 14-17 mm and the distance between the pipes (between the center of the pipe and the last $76 \mathrm{~mm}$ ). So the heat transfer between them evenly. On the basis of the distance between the pipes $76 \mathrm{~mm}$, the number of pipes is 8 determined equal.

The pipes are welded from the top and bottom of the upper collector pipe and the lower collector pipe, which is two galvanized iron pipes each diameter $27 \mathrm{~mm}$ and length $940 \mathrm{~mm}$ as shown in Figure 3 . 


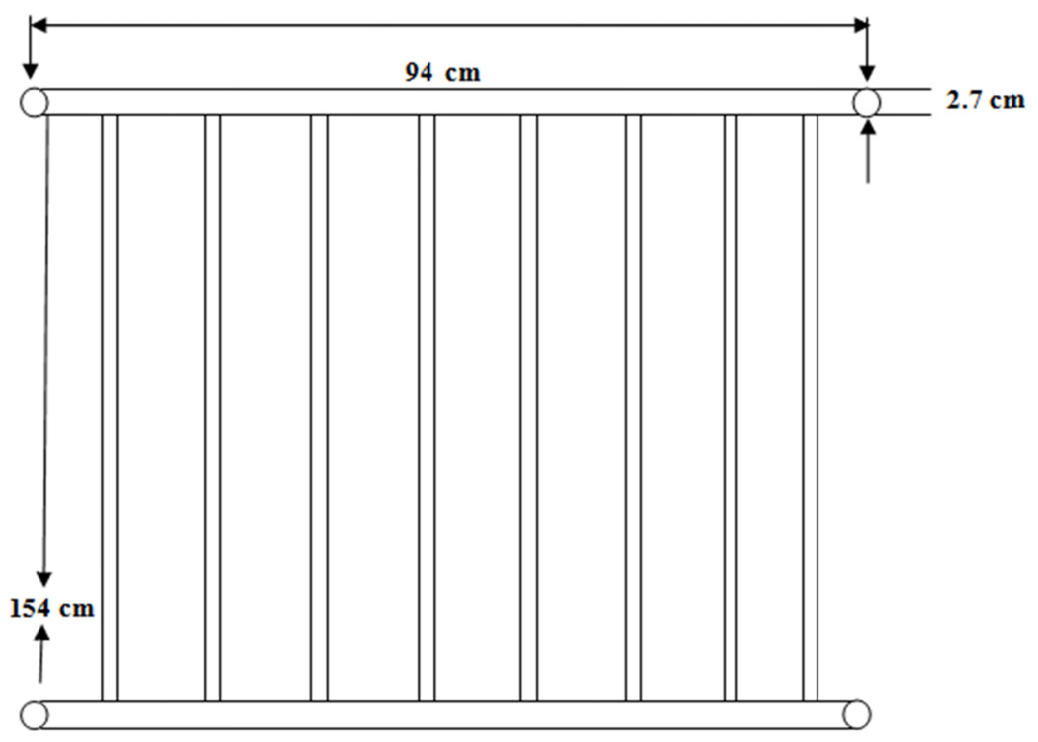

Figure 3. Installing the galvanized iron pipes with the upper and lower collector pipe

Galvanic welding method is used to connect galvanized iron pipes to the upper and lower combined pipes. The lower collector pipe is connected by an insulated tube at the bottom point of the tank through an insulated tube to the inlet of the lower collector pipe after the natural circulation inside the solar collector to heat the water by solar radiation. Isolated by the upper third of the tank as shown in Figure 4 and Figure 5.

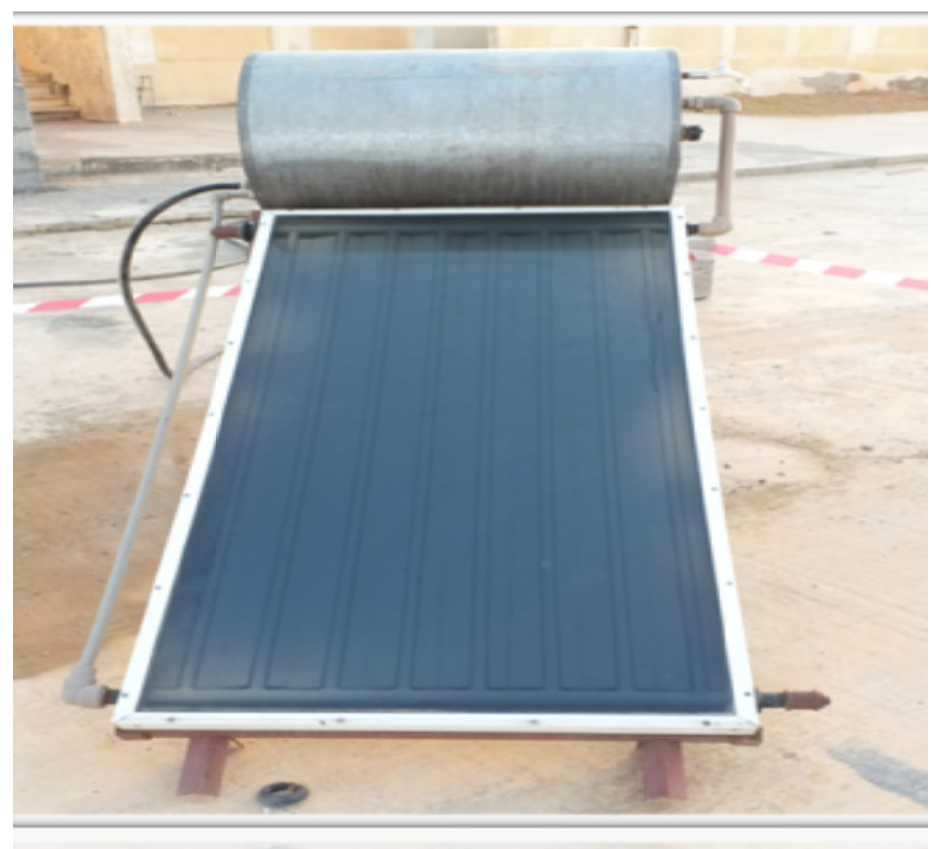

Figure 4. The interface of the solar heater and how the pipes are connected 


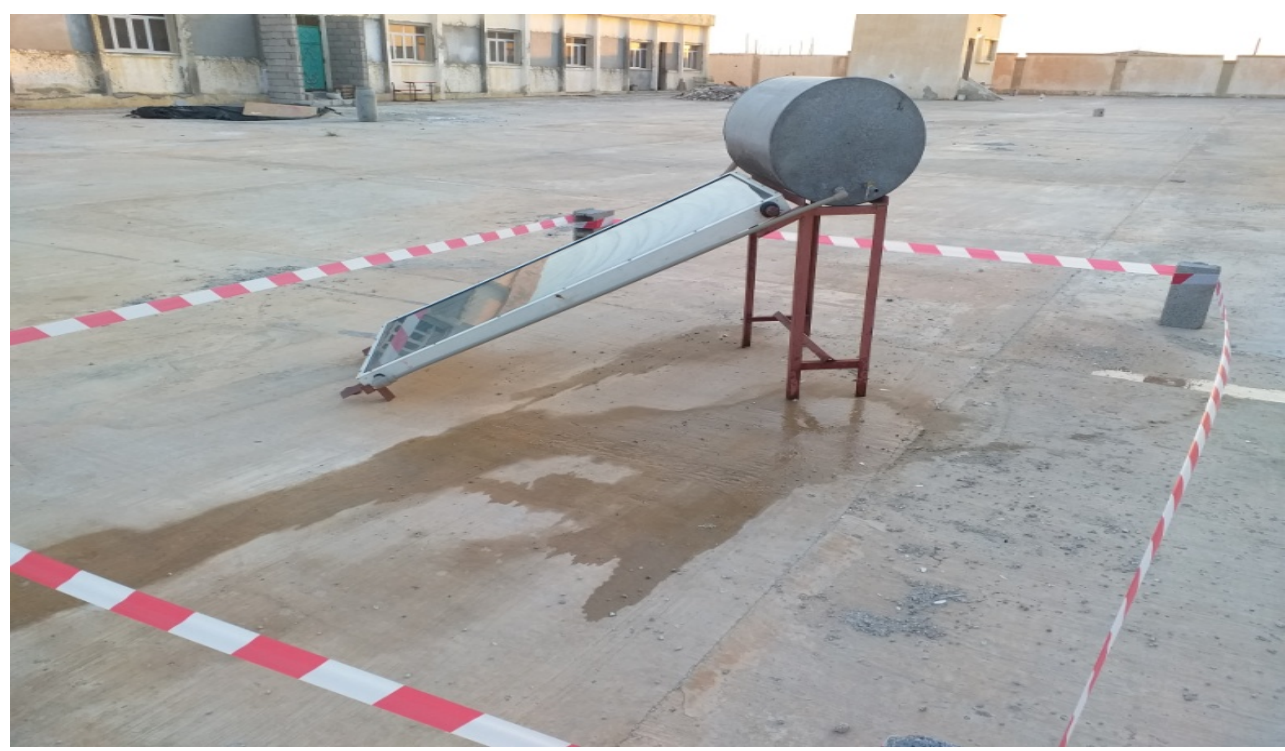

Figure 5.The connection between the pipes to the tank

\subsection{The Box}

The box is an external frame for the solar collector. The box is made of white aluminum with a thickness of 2 $\mathrm{mm}$ and a length $1740 \mathrm{~mm}$ and a width $830 \mathrm{~mm}$ and a height $920 \mathrm{~mm}$ as shown in Figure 4 which is holding the insulator between them and the absorbent plate after connecting process. The absorbent plate and water conductive pipe are placed in the box, and then closed from the bottom by a coarse iron plate of $2 \mathrm{~mm}$ thickness, and the box is closed from the top with a transparent white glass cover $3 \mathrm{~mm}$ of thickness, which is available in the market and is installed with an aluminum frame articulated so that it can be opened and closed for the possibility of cleaning the absorbent surface or making repairs inside the box .

The distance $25 \mathrm{~mm}$ between the absorbent surface and the glass was determined as the best distance to reduce the heat loss of the load between the range $25 \mathrm{~mm}$ to $35 \mathrm{~mm}$ Figure 5 shows the box and the base of the solar.
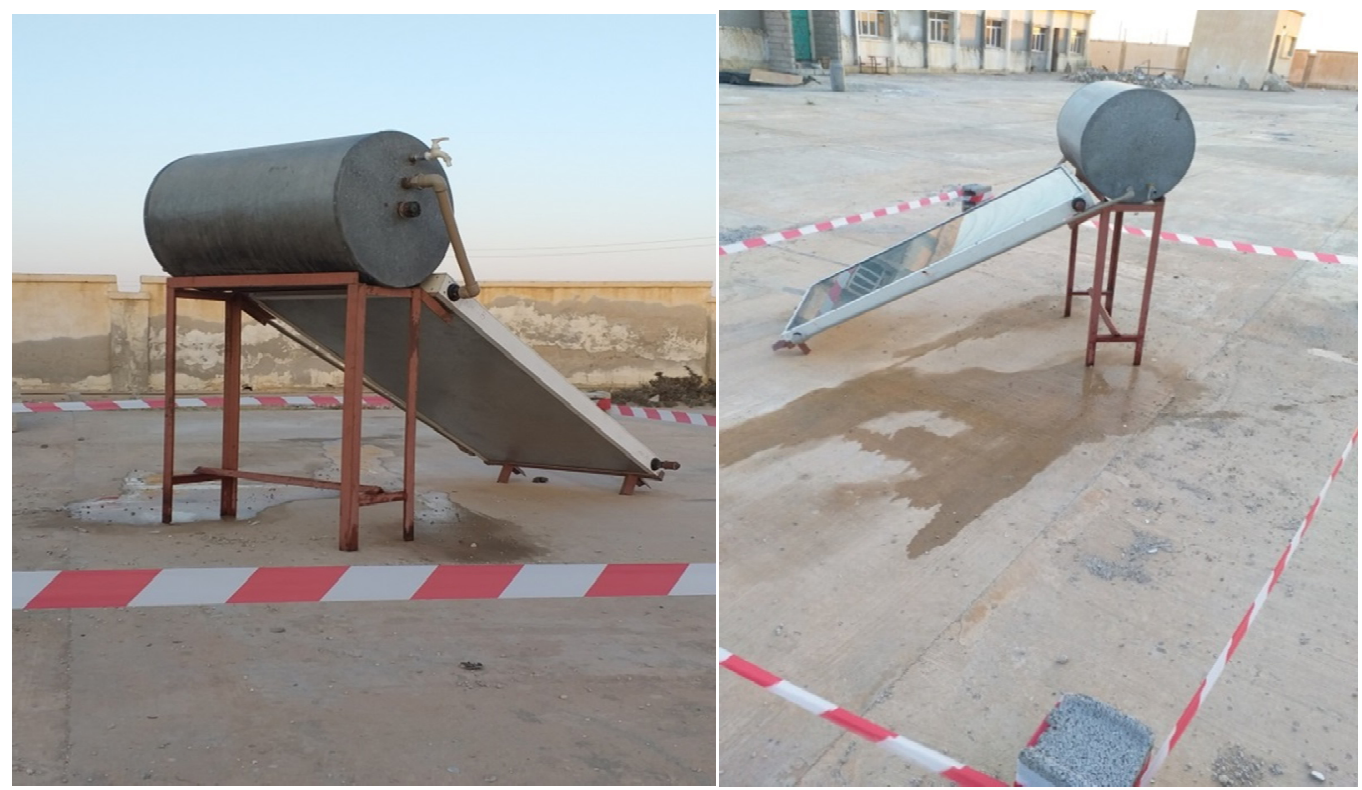

Figure 6. The pipes are connected in the side

The box with its contents has been fixed on an iron base. They are articulated so that the inclination of the collected surface on the vertical changes by the composition shown in Figure 6 . 


\subsection{Insulator}

The insulation is used to reduce thermal losses in the collector, in order to improve the efficiency of the solar collector, wool and glass wool insulator are used in the water tank with a thickness of $50 \mathrm{~mm}$, to reduce the loss of the tank throughout the year.

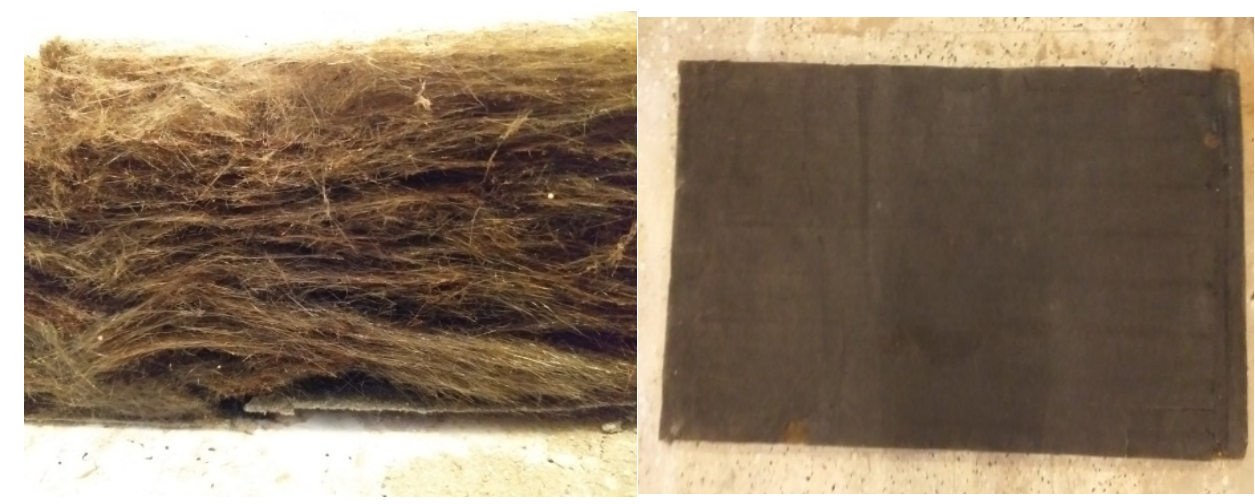

Figure 7. The thermal insulation to reduce the losses in the collector

\subsection{Reservoir}

The volume of the reservoir was selected on the basis that each square of the distance of the solar collector heated water in the range $(80-100)$ liters, and in the range $\left(52^{0} \mathrm{C}\right.$ to $\left.60^{\circ} \mathrm{C}\right)$ throughout the day. The tank was made of a pipe with a diameter $960 \mathrm{~mm}$, height $220 \mathrm{~mm}$ and a thickness $3 \mathrm{~mm}$, and closed two bases by welding and a number of valves were placed on the side of the tank and openings for the entry and exit of water, as well as the two pipes connected to the absorbent surface. The tank was insulated by glass wool thickness $50 \mathrm{~mm}$ and the thickness $50 \mathrm{~mm}$ of the insulation on the tank was chosen by drawing a curve linking the thickness of the insulator and the temperature slope for each thickness and the price of the insulator was found in a simplified way that $(50 \mathrm{~mm})$ as an insulator causes thermal regression Within $30^{\circ} \mathrm{C}$ as shown in Figure 8 .

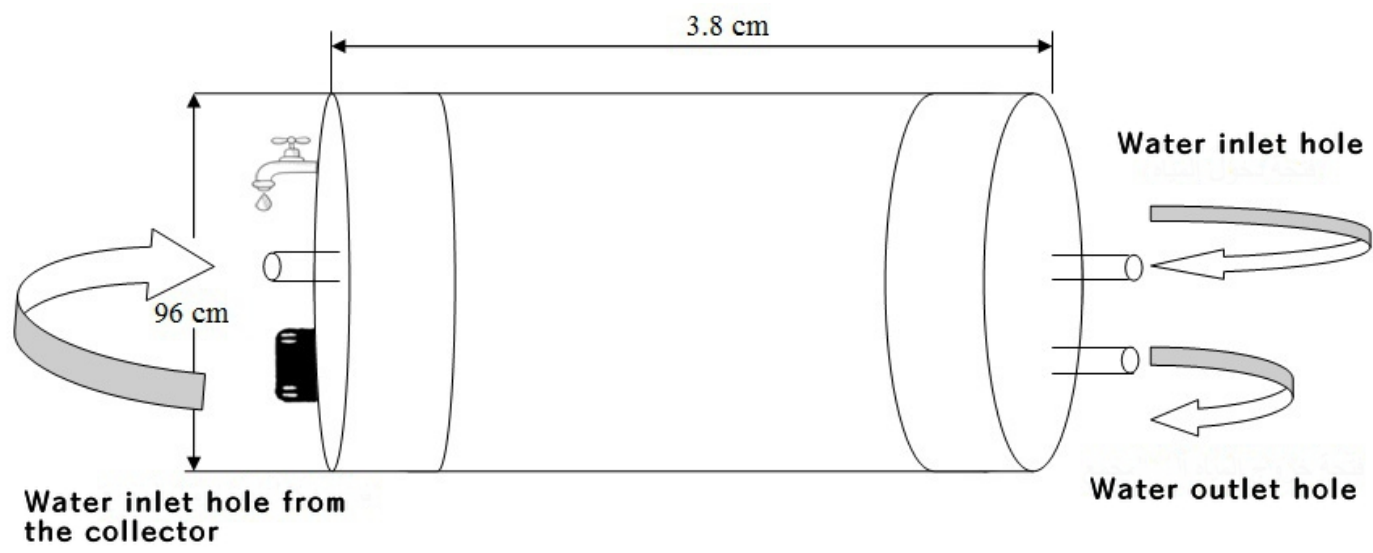

Figure 8. The tank inlet and outlet

\subsection{Measuring instruments used}

(1) Thermocouple type K (ice-3) thermometer to measure the absorption surface, glass cover and ambient air temperature, base temperature of the collector as shown in figure 9. 

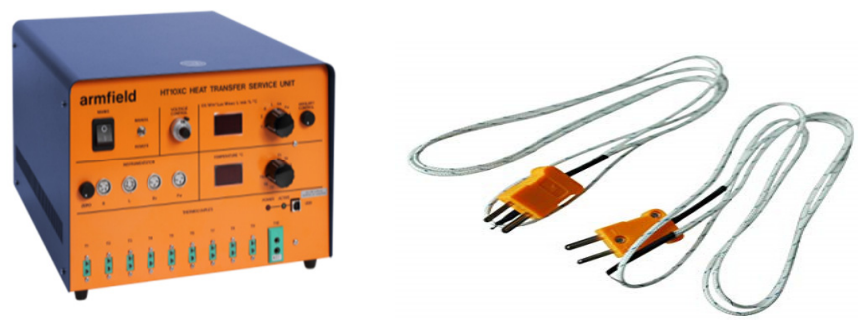

Figure 9. The service unit and thermal and thermocouples

(2) Pyranometer this device was obtained from the laboratory of the Department of Mechanical Engineering at Omar Al-Mukhtar University, which is used to measure the total solar radiation (the sum of direct, diffused and reflected radiation), and it is connected to data reader to read the results as shown in Figure 10. Pyranometer and data reader

(3)

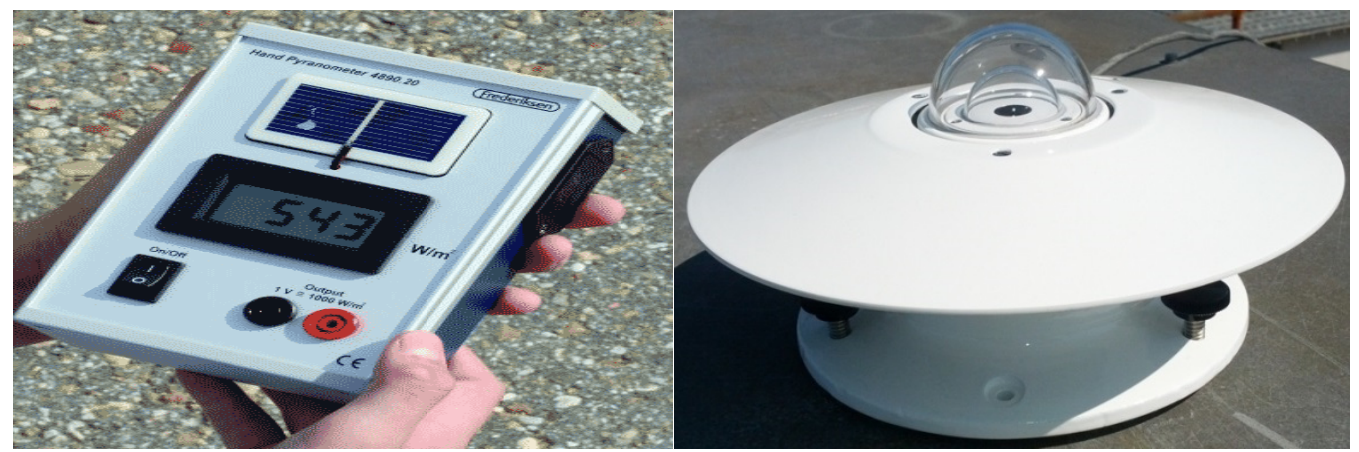

Figure 10. Pyranometer and data reader

\section{Results and Discussion}

The solar heater was placed at the Higher Institute of Comprehensive Professions at Tamimi in the area of Abu Al-Frais and was directed to the south of the geographical area and was used for measurements devices of the aforementioned. An initial reading was taken within four days, and the results were recorded as shown in the research.The solar heater was placed at an angle of latitude in the region of Abu al-Frais (Location 32.24N 23.17E). Due to time constraints, no results were recorded.

The average daily efficiency was also calculated by using equation (1) to calculate the efficiency of the solar collector for heating over four days from 9:00 to 6:00 pm. The average efficiency for Saturday 18/05/2019 was $66 \%$, and on $19 / 05 / 2019$ equals $54 \%$ and on $24 / 05 / 2019$ equals $52 \%$ also on $25 / 05 / 2019$ equals $56 \%$ for the angle of the complex $32^{\circ}$ for the town of Al-Tamimi Abu al-Frais.

$$
\eta=\frac{q u}{A c * I c}
$$

The maximum temperature of the absorption surface reached $76.9{ }^{\circ} \mathrm{C}$ which is almost the same as the previous reading. Circulation is normal for water. To increase the water temperature inside the tank, a small pump can be used to circulate water and thus obtain a high temperature. 


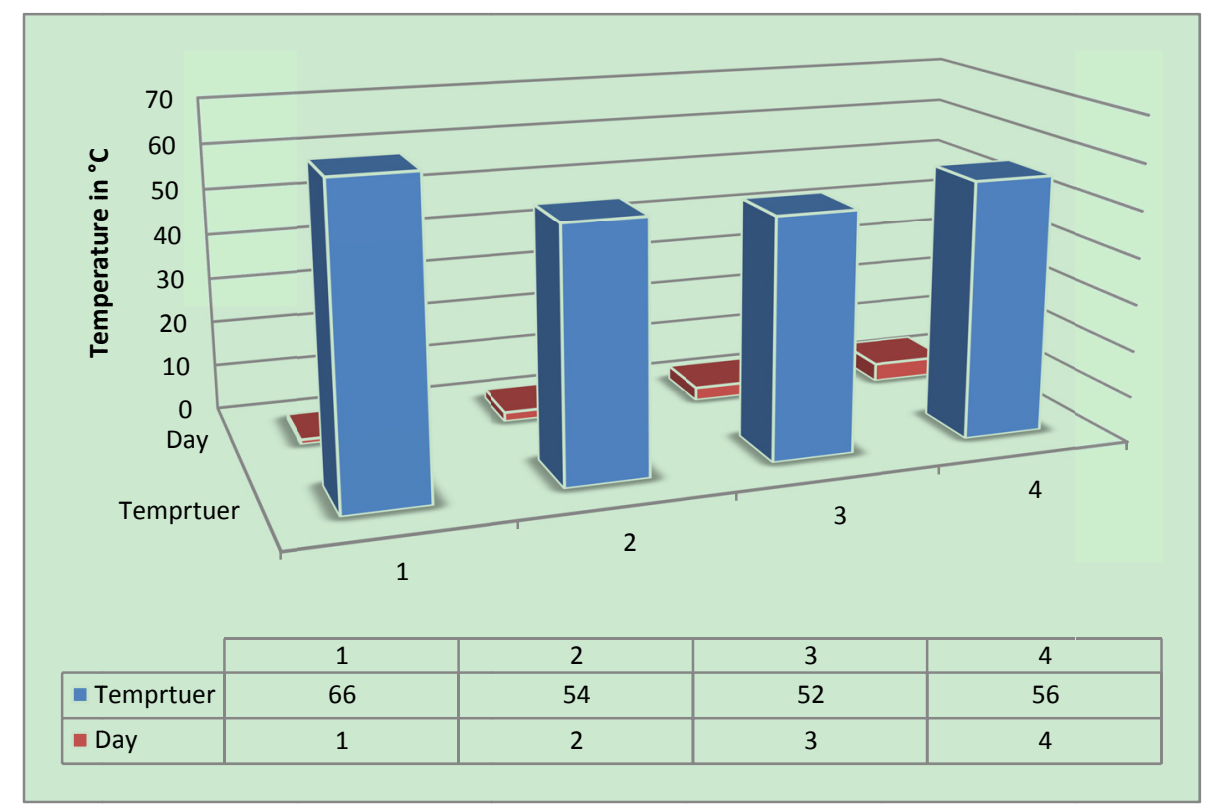

Figure 11. The highest temperature of the water for 4 days

\section{Conclusion}

The daily efficiency of the heater was found at $57 \% 12: 00 \mathrm{pm}$ and the average daily efficiency was around $57 \%$. The temperature in the tank is about $62^{\circ} \mathrm{C}$, which is sufficient for home use throughout the day.

\section{Recommendations}

- The solar heater should be tested to ensure its performance.

- The heat loss equations should be used for the heater.

- We also recommend using copper pipes instead of galvanized iron.

- To increase the water temperature inside the tank, a small pump can be used to circulate the water for a better temperature.

- The heater should be tested in summer, winter at intervals.

\section{References}

A.Azouz. (2019a). Experimental and Mathematical Modeling of A Solar Updraft Tower Power Plant. $2^{\text {nd }}$ Conference for Engineering Sciences and Technology Sabratah - Libya, 2, 75.

A.Azouz. (2019b). Theoretical and Experimental Investigation of Solar Updraft Tower Power Plant: A Case Study in El-Beida City. The 5TH SCIENTIFIC CONFERENCE OF BRIGHT STAR UNIVERSITY, INTERNATIONAL CONFERENCE OF RENEWABLE \& SUSTAINABLE ENERGY, 5, 14.

Akuffo, F., \& Jackson, E. (1988). Simulation studies on a compact solar water heater in the tropics. Solar \& wind technology, 5(3), 229-237. https://doi.org/10.1016/0741-983X(88)90020-3

Chamoli, S., \& Thakur, N. (2014). Exergetic performance evaluation of solar air heater having V-down perforated baffles on the absorber plate. Journal of Thermal Analysis and Calorimetry, 117(2), 909-923. https://doi.org/10.1007/s10973-014-3765-8

Chong, K., Chay, K., \& Chin, K. (2012). Study of a solar water heater using stationary V-trough collector. Renewable energy, 39(1), 207-215. https://doi.org/10.1016/j.renene.2011.08.002

Farahat, S., Sarhaddi, F., \& Ajam, H. (2009). Exergetic optimization of flat plate solar collectors. Renewable energy, 34(4), 1169-1174. https://doi.org/10.1016/j.renene.2008.06.014

Harikrishnan, S., Deepak, K., \& Kalaiselvam, S. (2014). Thermal energy storage behavior of composite using hybrid nanomaterials as PCM for solar heating systems. Journal of Thermal Analysis and Calorimetry, 115(2), 1563-1571. https://doi.org/10.1007/s10973-013-3472-x

Hu, Z., Li, A., Gao, R., \& Yin, H. (2014). Effect of the length ratio on thermal energy storage in wedge-shaped 
enclosures. Journal of Thermal Analysis and Calorimetry, 117(2), 807-816. https://doi.org/10.1007/s10973-014-3843-y

Ibrahim, A., Othman, M. Y., Ruslan, M. H., Alghoul, M., Yahya, M., Zaharim, A., \& Sopian, K. (2009). Performance of photovoltaic thermal collector (PVT) with different absorbers design. WSEAS Transactions on Environment and Development, 5(3), 321-330.

Leo, M. (1996). Keynote address: Bakun Hydro electric project seminar. Kuala Lumpur.

Mohamed, A. R., \& Lee, K. T. (2006). Energy for sustainable development in Malaysia: Energy policy and alternative energy. Energy policy, 34(15), 2388-2397. https://doi.org/10.1016/j.enpol.2005.04.003

Mohsen, M. S., Al-Ghandoor, A., \& Al-Hinti, I. (2009). Thermal analysis of compact solar water heater under local climatic conditions. International Communications in Heat and Mass Transfer, 36(9), 962-968. https://doi.org/10.1016/j.icheatmasstransfer.2009.06.019

Pandey, A., Tyagi, V., Rahim, N., Kaushik, S., \& Tyagi, S. (2015). Thermal performance evaluation of direct flow solar water heating system using exergetic approach. Journal of Thermal Analysis and Calorimetry, 121(3), 1365-1373. https://doi.org/10.1007/s10973-015-4566-4

Sarhaddi, F., Farahat, S., Ajam, H., Behzadmehr, A., \& Adeli, M. M. (2010). An improved thermal and electrical model for a solar photovoltaic thermal (PV/T) air collector. Applied energy, 87(7), 2328-2339. https://doi.org/10.1016/j.apenergy.2010.01.001

Sharma, N. (2014). Experimental investigation of the performance of an indirect-mode natural convection solar dryer for drying fenugreek leaves. Journal of Thermal Analysis and Calorimetry, 118(1), 523-531. https://doi.org/10.1007/s10973-014-3949-2

Vickers, N. J. (2017). Animal Communication: When I'm Calling You, Will You Answer Too? Current Biology, 27(14), R713-R715. https://doi.org/10.1016/j.cub.2017.05.064

Zondag, H. (2008). Flat-plate PV-Thermal collectors and systems: A review. Renewable and Sustainable Energy Reviews, 12(4), 891-959. https://doi.org/10.1016/j.rser.2005.12.012

\section{Copyrights}

Copyright for this article is retained by the author(s), with first publication rights granted to the journal.

This is an open-access article distributed under the terms and conditions of the Creative Commons Attribution license (http://creativecommons.org/licenses/by/3.0/). 